\title{
Brief Discussion on Smart Power in Journalism and Communication
}

\author{
Keke LIU \\ University of Jinan, Shandong 250022, China
}

\begin{abstract}
By inquiring into and analyzing the source and recognition of the "smart power" in journalism and communication, the author put forward the ways to improve the smart power in journalism and communication, which include the art of news transmission, the reform and innovation of journalism, the team-building of news communication, the ability of using the new media as well as the information disclosure which should be timely, full, transparent and effective.
\end{abstract}

KEYWORD: Journalism and communication; Smart power; Media; Information

Journalism and communication are the productivity that reflects the hard power of the media as well as the impact that mirrors its soft power in cultural transmission[1]. Smart power in journalism and communication is an overall strategy combining both hard and soft power.

\section{SMART POWER IN JOURNALISM AND COMMUNICATION}

\subsection{The source of smart power}

The original term, "smart power", was first proposed by American scholar, Suzanne Nossel, in Foreign Affairs magazine. She emphasized that "smart power" was an ability that can combine hard and soft power into a winning strategy to achieve U.S. foreign policy goals. Later, the former U.S. deputy secretary of state, Richard Armitage and the famous scholar, Joseph Nye published a research report titled "Strategy on Smart Power", clearly stating that the U.S. should use "smart power" to transform the foreign strategy in order to help U.S. get rid of the current mess and renew its leadership in the world[2].

Neither hard nor soft, the smart power is an overall strategy combining both. The essence of the competition of the world, groups and men is the competition of powers. But powers also can be classified. With the improvement of social science research, people classified them as hard and soft power in the early years. The so-called hard power refers to the visible and touchable material force, such as economy, science and technology, military, etc., which is dominant and basic for all other forces.
Beyond hard power, the soft power refers to the influence and attraction of culture, values, systems, growth models, ways of life, ideology etc. It is like the software for a computer. If you use it well, you can make the value and role of hard power maximum and have great influence on other soft powers as well.

\subsection{Smart power in journalism and communication}

In the field of news media, "soft power" is mainly focused on how to achieve the ultimate aim of the soft power by improving the transmissibility of the news media and the leading-force of the public opinion and by expanding the influence of the news media itself.

The transmission and guide-force functions, which the news media has, make it an important and effective tool that can reflect and increase the "soft power".

Through reports and news comments, mass media could have influence on the society and guide the public opinions to aggregate the public and unite the national forces. It is the strength and value of the "soft power".

To utilize the smart power in news transmission is to use wisdom and skills, which means to display and express the national strength and influence by the methods of media and at the same time to develop and show its transmissibility of information and leading-force of public opinion as well. This is a display of a kind of ability and level, which requires sharp thinking, agile methods and great skills to achieve. 
"Smart power" is a skill as well as a type of ability. It turns out that it is not enough for a country to only have the "strength" (the hard power) and the "influence" (the soft power). It must smartly and adequately use its strength and influence so as to beat the opponents and achieve the goals.

\section{WAYS TO IMPROVE THE SMART POWER IN JOURNALISM AND COMMUNICATION}

\subsection{To stress the art of propaganda}

"Non-elegant words will not become popular." From the journalistic perspective, the word "elegant" means that not only the news reports should be based on abundant facts, but also the adept art and techniques of media transmission should be used to guide the public opinion. Lenin once said that the art of each propagandist lay in using the most effective approach to influence the audience[3]. To enhance the capability of properly guiding the public opinion, we must stress the art of propaganda and spread the views in artistic way, thus maximizing the attraction of audience.

To improve the capacity of news transmission, it is necessary to work hard in intensifying the attraction and appeal. It is proved that it will work better to guide the public opinion using the methods that the public are willing to accept to spread the voice from the Party and the government. Some of the media are very popular not only because of the authoritative, deep, timely news, but also because of the various, lively and vivid forms of programs and news report. In order to produce the effect to influence the public, it must be concise to the point, easy to understand, vivid and moving. In order to make the journalism more affable and reliable, it should be the must to highlight the feature, talk less, analyze deeply, especially insist the people-oriented policy to unify the Party's views and the people's wills as well as the correct guidance and good understanding of the public opinion. The news report and propaganda should be focused on the grassroots level, using people's language, public examples and the forms beloved by people.

The core of improving the ability of news propagation is to master the "degree" of it. Relying on science, the expression of "degree" also requires arts. From a propaganda campaign or an editorial choice to the deliberation of words, all these are the process of appreciating the "degree". The news transmission should be not only effective but also proper and right. In order to achieve that, it must be done to correctly hold the report scale, quantity and frequency and to study the audience's psychology, mentality and emotion as well. Thus, it could moderate the degree and avoid the negative effects causing by simplification, absoluteness and unilateralism.

Firstly, the topics for news propaganda should be perfectly designed. After analyzing the trend of news transmission, the audience's psychology and the state of public sentiment, the media should positively set the topics. This is because the correct chose of news topic always can get a head start and make more powerful influence on the audience. So the analysis of public opinion, the topic setting and the guidance according to circumstance are the "trilogy", which can scientifically and subtly guide the public opinions. Among them, the analysis of public opinion is particularly important.

Secondly, a correct direction of the news transmission should be guided. The so-called "correct direction" means that the news reports should head towards the path, which is fit, for the Party's basic theory, line and policy as well as the fundamental interests of our country and nation. If the direction goes astray or even reverse, the more powerful the influence and control of the news media is, the more cataclysmic and dangerous the results will be. Therefore, in order to hold the correct direction, the pertinency of mass media must be unequivocally enhanced.

\subsection{To innovate the news transmission}

Journalism means constantly evolving with "innovation" as its core[4]. The focus of innovation lies not only in effectiveness but also in the new content and way of news reports. Only when reform and innovation of journalism are bravely and highly used can we have a new breakthrough in the capacity of public guidance.

We should control the new trend of its embodiment and focus media. With the development of technology and the sharp increase of the amount of information, the tendency of the audience requirements has changed from "being forced to accept" to "actively choosing". As the audience demand has increasingly diversified, it's very hard for one medium to satisfy with all people's demand, so it has to choose part of the audience as its target object. Hence, it requires the medium to reorient itself according to difference and interests of the audience and to find its position in society and market by using the differentiation strategy. At present, homogeneity, to some extent, still exists in some media, especially in some affiliates and tabloids, making people gradually lose their interests. Therefore, it is necessary for various media to study the new change of masses demand, to constantly adjust the contents of report and to meet the multilayer and diversified information demand of the audience. 
Means of journalism should be innovated. With continuous improvement, the form and practices of our news report have become more and more rich and popular. But there are still a lot need us to do. At the same time, we must try our best to avoid the phenomena such as the documentation of policy propaganda, the conceptualization of work reports, the standardization of conference reports or the stereotypes of typical report and instead to achieve the diversifications of news topic, form and style. When we report conferences or leader's activities, the newsworthy must be on the focus to make the report "true to life". When we report a typical issue, we must make the typical high-minded as well as reliable and amiable. When we report key works, we must make the report have many sides and angles and must avoid the identical and oneness of the content and form. In order to enhance the expressive force of news transmission, it is necessary to fully use various report forms, such as live images, synchronized voice, chart, remark, etc.

\subsection{To build news corps}

It is the lofty mission for the journalists to improve the capacity of news transmission. Thus it requires the journalists to have some qualities, such as the requisite stock of knowledge, working style, sense of responsibility and moral cultivation.

The news report will not be well done without solid foundation. In this respect, many old-timers have set excellent examples. They were famous journalists who thoroughly understood Marxism as well as specialists and scholars who were not only knowledgeable but also brilliant. So all the journalists must put learning at the first position and consider it as a lifelong process. We must learn from books as well as practice; ask for advice from colleagues and experts as well as the masses; dig into the expertise as well as other respects of knowledge, such as economy, politics, sociology, psychology and so on. As a journalist, we should try our best to be an excellent one who is studyoriented, knowledge-based and technocratic or to be a well-known reporter, editor, commentator and presenter who will be loved by the masses.

A journalist also must have good professional ethics. In ancients, people were encouraged to set virtue, win merit then to expound his ideas in writing. Only when we first set our virtue can we express the opinions from people and win the merits for the epic. In order to constantly add luster to the journalism of our Party, all the journalists should obey the press professional ethics, consciously accept the social supervision, resolutely resist the paid news, fake news and lowbrow report, fulfill socialist concept of honor and disgrace and become the defenders of positive image of news corps.

\subsection{To improve the ability to use emerging media}

Improving the ability to use emerging media, we could try our best to be an adept in journalism. In the conditions of informatization, all the journalists should deeply study the rules and art of news transmission and be good at using the emerging media, like the Internet or cellphone, in the news report. At the same time, we must actively guide the online public opinion and keep close watch on the online public sentiment so that we could find the first signs of all kinds of problems online. We also must meet the new needs of information technology on news interview, editing, producing and transmission, grasping the features of different media types (such as newspaper and magazine, radio and television, the Internet, etc.), mastering the equipment technology of multimedia transmission and modern media and improving new business skills. Thus, we could become the specialized journalists of the new era.

"To successfully and correctly guide the public opinion, we must carry out a new all-round layout of the news report and make the major opinion be the mainstream through different media platforms."[5] And that would require the mainstream media as well as the emerging one to play their roles at the same time. Therefore, following the objective law of the media development, it is a necessity to strengthen mainstream media and emerging media at the same time.

Nowadays, with the boom of the media, newspapers, networks, television and radio stations offer the journalists a large number of platforms to use. Statistically, at present there are over $500,000,000$ mobile phone users in China and the number of the Internet users is over 200,000,000, websites more than 1,500,000 and blogs over 70,000,000. In China, there are also nearly 300 domestic radio broadcast stations, about 1,900 newspapers, over 9,400 magazines and more than 290 TV stations.[6] In order to take good advantage of these platforms and amplify the voice, journalists should pay attention to the propaganda and strictly abide by the professional moral and rules of journalism.

\subsection{To open the information timely, fully, transparently and effectively}

Information publicity should be focused on opening the authoritative information at the first, improving time-effectiveness and adding transparency, in which time-effectiveness and transparency are the essences of journalism purchased by journalists diligently.

Journalism needs art and technique as well as the smart power. Ms. Fu Ying, Chinese ambassador to the U.K., summarized the concepts and methods of external propaganda as "speaking early, fully and clearly".[7]As a diplomat, Ms. Fu can directly 
communicate with the foreign people and be familiar with the western public opinion environment, so those concepts and methods she has experienced and practiced by herself are worth thinking and learning.

\section{REFERENCES}

[1] Li Changchun's speech, Guangming Daily, June 26, 2009

[2] Joseph S. Nye, Jr., Foreign Policy, July-August, 2009
[3] Page 321, Volume 17, The Collected Works of Lenin, People's Press 1986

[4] Page 567, Volume 1, The Selected Works of Jiang Zemin, People's Press 2006

[5] Zheng Baowei \& Qi Tao, News and Writing, $7^{\text {th }}$ Issue, 2008

[6] Hua Qing, People's Daily, November, 3, 2008

[7] Chinese ambassador to the U.K., Ms. Fu Ying's Speech on Foreign Affairs, China Comment, $15^{\text {th }}$ Issue, 2009 